\title{
CONF-970582--2 \\ Comparison of Experimental and Analytical Methods to Evaluate Thermal Bridges in Wall Systems
}

\author{
André O. Desjarlais \\ Energy Division \\ Oak Ridge National Laboratory \\ and \\ Alex G. McGowan \\ Enermodal Engineering Ltd. \\ Kitchener Ontario \\ N2K 3S2 Canada
}

To be presented and published in the $3^{\text {rd }}$ ASTM Symposium on

Insulation Materials: Testing and Applications: $3^{\text {rd }}$ Vol. ASTM STP 1320

being held in Quebec

May 15, 1997

Research sponsored by

the Office of Building Technologies and

Department of Energy

\begin{abstract}
The submitted manuscript has been authored by a contractor of the U.S. Government under contract No. DEAC05-960R22464. Accordingly, the U.S.

Government retains a nonexclusive, royalty-free license to publish or reproduce

the published form of this contribution, or

allow others to do so, for U.S. Government

purposes.
\end{abstract}

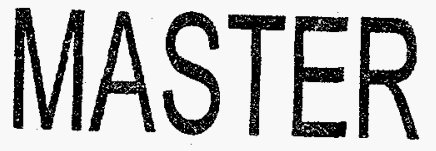

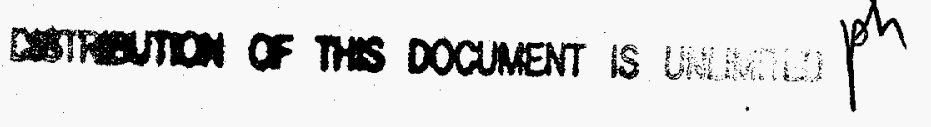

Prepared by the

OAK RIDGE NATIONAL LABORATORY

Oak Ridge, Tennessee 37831

managed by

LOCKHEED MARTIN ENERGY RESEARCH CORP.

for the

U.S. DEPARTMENT OF ENERGY

under contract No. DE-AC05-96OR22464 


\section{DISCLAIMER}

This report was prepared as an account of work sponsored by an agency of the United States Government. Neither the United States Government nor any agency thereof, nor any of their employees, make any warranty, express or implied, or assumes any legal liability or responsibility for the accuracy, completeness, or usefulness of any information, apparatus, product, or process disclosed, or represents that its use would not infringe privately owned rights. Reference herein to any specific commercial product, process, or service by trade name, trademark, manufacturer, or otherwise does not necessarily constitute or imply its endorsement, recommendation, or favoring by the United States Government or any agency thereof. The views and opinions of authors expressed herein do not necessarily state or reflect those of the United States Government or any agency thereof. 


\section{DISCLAMMER}

Portions of this document may be illegible in electronic image products. Images are produced from the best available original document. 
André O. Desjarlais ${ }^{1}$ and Alex G. McGowan ${ }^{2}$

COMPARISON OF EXPERIMENTAL AND ANALYTICAL METHODS TO EVALUATE THERMAL BRIDGES IN WALL SYSTEMS

REFERENCE: Desjarlais, A.O. and McGowan, A.G., "Comparison of Experimental and Analytical Methods to Evaluate Thermal Bridges in Wall Systems," Insulation Materials: Testing and Applications: Third Volume, ASTM STP 1320, R.S. Graves and R.R. Zarr, Eds., American Society for Testing and Materials, 1997.

ABSTRACT: Twelve ASTM C0236 guarded hot box experiments have been performed on wall systems containing a variety of thermal bridges. All of the wall systems included steel framing. Six walls also had a concrete block wall system and a concrete slab to simulate a wall/floor intersection. Thermal bridges included in the wall systems included steel studs, steel tracks, steel stud/track joints, fasteners (steel framing system), concrete slab, metal bolts and angle iron, and brick ties (concrete block wall).

Two-dimensional finite difference modelling was also employed to characterize the wall systems. The experimental test data was used to tune and ultimately validate the computer simulation model. The average variation between the tested and simulated wall system R-Values was $3.3 \%$ and ranged from -3.4 to $+7.4 \%$. The model was then used to determine the thermal impact of each individual thermal bridge.

Beside the standard complement of temperature sensors that are traditionally used for these laboratory experiments, additional sensors were installed near each thermal bridge to define the area and magnitude of the thermal distortion caused by the thermal bridge. These thermal bridges were analytically simulated and the additional heat flux due to each thermal bridge was computed.

This paper summarizes the experimental and analytical analyses used to characterize the wall systems and concentrate on the thermal impact each type of thermal bridge has on the overall performance of the wall systems.

\footnotetext{
${ }^{1}$ Staff Engineer, Oak Ridge National Laboratory, Oak Ridge, TN 37831.

${ }^{2}$ Vice President, Enermodal Engineering Ltd., Kitchener, Ontario N2K 3S2, Canada.
} 
KEYWORDS: Guarded hot box, thermal performance, building envelope, R-value, wall systems, heat transfer, computer simulation.

A thermal bridge is defined as a part of the building envelope system that produces a locally higher heat transfer rate through the building envelope system [1]. Most often, thermal bridges are created when structural components interrupt the insulation layer. In wall systems, some typical thermal bridges are steel and wood studs, floor slabs, metal ties, and flashings. In addition to increasing heat losses, the surface temperatures near the thermal bridge are impacted; the reduction of the interior surface temperature near the thermal bridge during winter conditions can increase the potential for condensation, resulting in mold and mildew growth, staining, and potential structural degradation. Therefore, significant energy savings, improved air quality, and enhanced durability would result if thermal bridging issues were appropriately addressed.

A research project to address these problems [2] has been completed. Twelve wall assemblies were analysed through a combination of detailed guarded hot-box measurements and finite-volume heat transfer analysis. Using the measured results to validate the simulation models, additional thermal bridge assemblies were analysed with the computational method. This paper compares the performance of several different thermal bridges using the results from physical testing and computer simulation.

\section{EXPERIMENTAL AND NUMERICAL PROCEDURES}

Twelve different wall assemblies were constructed and tested in accordance with ASTM C0236-89, Standard Test Method for "Steady-State Thermal Performance of Building Assemblies by Means of the Guarded Hot Box [3]. The Oak Ridge National Laboratory (ORNL) Rotatable Guarded Hot Box (RGHB) was used for these experiments. The details of all of the wall assemblies were specified by the client. The first six wall assemblies were metal-frame wall systems. A $10 \mathrm{ft}$. $(3.1 \mathrm{~m})$ high by $8 \mathrm{ft}$. $(2.4 \mathrm{~m}$ ) wide test panel was constructed for each wall assembly (see Fig. 1). The wall assemblies were identified as A.1, A.2, A.3, B.1, B.2, and B.3. These wall assemblies were comprised of:

A.1 5/8-in. (16 mm) gypsum wallboard;

nominal 4-in. (100 mm) C-shaped 18-gauge steel studs (1-5/8-in. or $41 \mathrm{~mm}$ flange) 24 inches (610 mm) o.c., with R 11 (RSI 1.94) full-width paper-faced (one side) glass fibre insulation batts. The construction includes top and bottom tracks the same thickness as the studs spaced $8 \mathrm{ft}$. $(2.4 \mathrm{~m})$ apart. These two additional tracks are not part of the wall system that is being measured as they are outside of the metered area of the guarded hot box; and 
5/8-in. $(16 \mathrm{~mm})$ gypsum wallboard.

A.2 Same as A.1, with nominal 1 -in. (25 mm) expanded polystyrene (EPS) added to the exterior side between the studs and the gypsum wallboard.

A.3 Same as A.1, with nominal 1.5 -in. $(38 \mathrm{~mm}$ ) expanded polystyrene (EPS) added to the exterior side between the studs and the gypsum wallboard.

B.1 5/8-in. (16 $\mathrm{mm}$ ) gypsum wallboard; nominal 6-in. (150 mm) C-shaped 18-gauge steel studs (1-5/8-in. or $41 \mathrm{~mm}$ flange) 24 inches $(610 \mathrm{~mm})$ o.c., with R 19 (RSI 3.35) full-width paper-faced (one side) glass fibre insulation batts. The construction includes top and bottom tracks the same thickness as the studs spaced $8 \mathrm{ft}$. $(2.4 \mathrm{~m})$ apart; and $5 / 8$-in. $(16 \mathrm{~mm})$ gypsum wallboard.

B.2 Same as B.1, with nominal 1-in. (25 mm) expanded polystyrene (EPS) added to the exterior side between the studs and the gypsum wallboard.

B.3 Same as B.1, with nominal 1.5-in. (38 mm) expanded polystyrene (EPS) added to the exterior side between the studs and the gypsum wallboard.

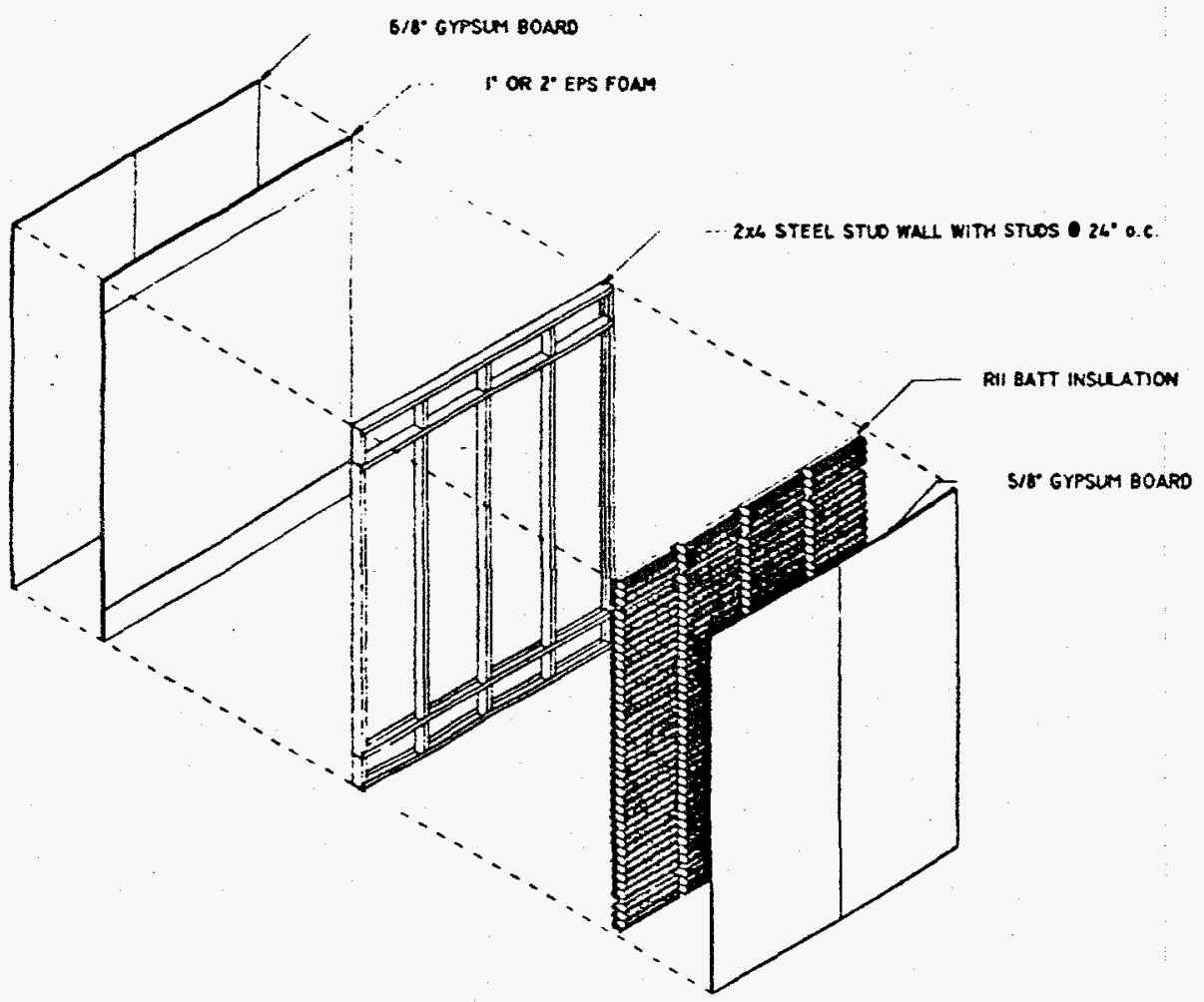

FIG. 1 -- Schematic of steel wall systems evaluated in the guarded hot box (Test series A and B). 
The remaining six wall assemblies were a combination of metal framing and masonry wall systems. Again, a $10 \mathrm{ft}$. $(3.1 \mathrm{~m})$ high by $8 \mathrm{ft} .(2.4 \mathrm{~m})$ wide test panel was constructed for each wall assembly (see Fig. 2). The wall assemblies were identified as C.1, C.2, C.3, D.1, D.2, and D.3. These wall assemblies were comprised of:

C.1 1/2-in. (13 mm) gypsum wallboard;

nominal 4-in. (100 mm) C-shaped 18-gauge steel studs (1-5/8-in. or $41 \mathrm{~mm}$ flange) 24 inches $(610 \mathrm{~mm})$ o.c., with uninsulated cavities. The construction includes top and bottom tracks the same thickness as the studs;

nominal 8-in. $(200 \mathrm{~mm})$ concrete block wall;

3-in. (76 mm) vented air space; and

two layers of $3 / 8$-in. $(9 \mathrm{~mm})$ gypsum wallboard, to provide the equivalent thermal resistance of a 4 -in. $(100 \mathrm{~mm})$ brick veneer. Although brick would have been preferred, the selection of gypsum wallboard allowed ready access the airspace behind the "brick."

C.2 Same as C.1, with nominal 1 -in. $(25 \mathrm{~mm})$ extruded polystyrene (XEPS) added to the exterior of the concrete block layer, leaving a 2 -in. $(50 \mathrm{~mm})$ vented cavity.

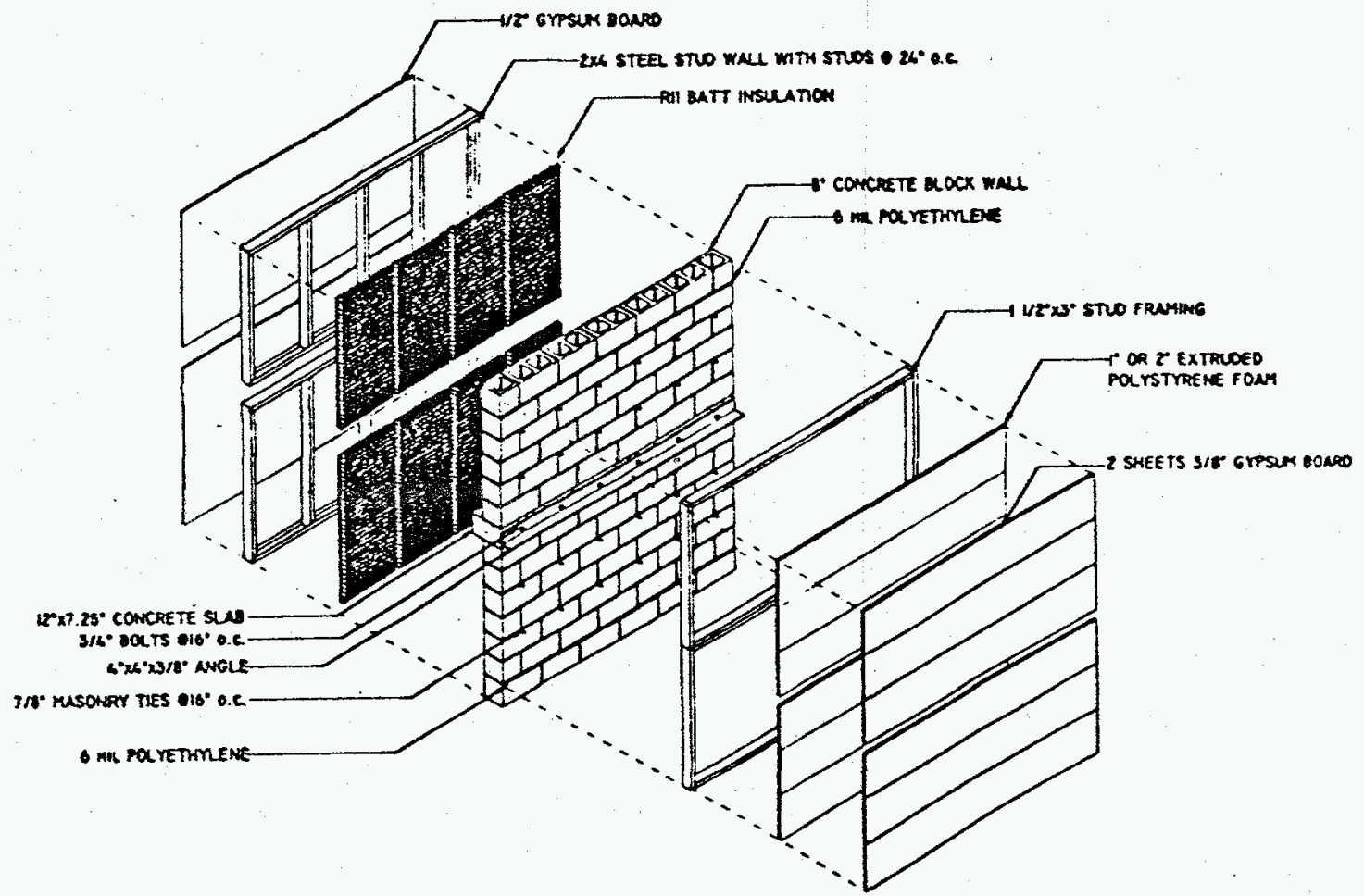

FIG. 2 -- Schematic of concrete block wall systems evaluated in the guarded hot box (Test series $\mathrm{C}$ and $\mathrm{D}$ ). 
C.3 Same as C.1, with nominal 2-in. $(50 \mathrm{~mm}$ ) extruded polystyrene (XEPS) added to the exterior of the concrete block layer, leaving a 1 -in. $(25 \mathrm{~mm})$ vented cavity.

D.1 Same as C.1, with R 11 (RSI 1.94) full-width paper-faced (one side) glass fibre insulation batts in steel stud cavity.

D.2 Same as D.1, with nominal 1-in. $(25 \mathrm{~mm})$ extruded polystyrene (XEPS) added to the exterior of the concrete block layer, leaving a 2 -in. $(50 \mathrm{~mm})$ vented cavity.

D.3 Same as D.1, with nominal 2-in. (50 mm) extruded polystyrene (XEPS) added to the exterior of the concrete block layer, leaving a 1 -in. $(25 \mathrm{~mm})$ vented cavity.

In all masonry wall systems, the interior gypsum wallboard, steel stud cavity, and concrete block wall were penetrated halfway up the height of the specimen by a concrete slab to represent a typical floor slab in a high-rise construction detail (see Fig. 2). The thermal barrier is also compromised by a steel shelf angle anchored to the concrete slab, which is intended to support the exterior brick wythe.

During testing, the air temperatures for the exterior climate and interior metering chambers were maintained at approximately $50^{\circ} \mathrm{F}\left(10^{\circ} \mathrm{C}\right)$ and $100^{\circ} \mathrm{F}\left(38^{\circ} \mathrm{C}\right)$, with natural convection on the metering side and moderate air flow on the climate side (to ensure a uniform climate-side temperature). These temperatures were selected to match the temperatures used for obtaining the material thermal properties. All wall assemblies were instrumented and tested in accordance with ASTM C0236. Additional thermocouples were placed in locations determined through the use of preliminary finite-volume modelling (to identify regions where thermal gradients would be of interest). Except the metal components and the concrete block, the apparent thermal conductivity of all materials used in the construction of the wall assemblies were measured in accordance with ASTM C0518-91, Standard Test Method for "Steady-State Heat Flux Measurements and Thermal Transmission Properties by Means of the Heat Flow Meter Apparatus' [4]. Metal components were evaluated with a laser flash diffusivity technique in accordance with ASTM E1461-92, Standard Test Method for "Thermal Diffusivity of Solids Using the Flash Method" [5]. The concrete block were measured by ASTM C0236-89, Standard Test Method for "Steady-State Thermal Performance of Building Assemblies by Means of the Guarded Hot Box" prior to the completion of the construction of wall assembly $C$. These data were used as data input in the finite-volume analysis.

The wall assemblies were also modelled using FRAME [6], a 2D finite-volume heat transfer program. Simulations are performed by drawing a cross-section of the wall assembly to be analysed (using a simple CAD interface), applying the as-tested boundary conditions to the structure, and refining the finite-volume grid as required to provide increased accuracy in areas of interest. The program determines temperature distributions and heat transfer within the structure, and thermal resistance through areas of interest. 
The simulation method was previously described and validated for the steel wall assemblies reported in this paper [7]. A key conclusion of that report was the need to assign a contact resistance between the studs and the sheathing.

In addition to predicting the overall thermal performance of the wall assemblies, the simulation model was used to predict the temperature profiles near each thermal bridge. These temperature predictions were compared to the data compiled from thermocouple rakes that had been installed on the test assemblies. For the A and B Series, temperature rakes had been applied on each side of the wall assembly near a stud, a track, and near the intersection of a stud and track. For the $\mathrm{C}$ and $\mathrm{D}$ series, temperature rakes were applied on the metering side of the wall assembly near a stud, a track, and above and below the concrete slab. On the climate side, a temperature rake was installed near a metal tie.

\section{RESULTS}

\section{Thermal Performance of Wall Assemblies}

A summary of the measured and simulated R-Values are presented in Table 1. On average, the difference between the experimental and numerical methods was $3.3 \%$, ranging from $-3.4 \%$ to $+7.4 \%$. The agreement for the Series $A$ and $B$ was better than for the Series $\mathrm{C}$ and D walls. For the Series A and B walls, the maximum deviation $(+4.0 \%)$ was obtained on the 2 by 6 wall system with 1.5 -in. $(38 \mathrm{~mm}$ ) EPS sheathing. The wall assembly that displayed the greatest deviation is Wall Assembly C.2, the masonry wall system with uninsulated steel stud cavities and 1 -in. (25 mm) XEPS sheathing.

\section{"Bonus" R-value}

It is interesting to note that for the A and B Series, test results indicate that the addition of insulating sheathing (1-in. or $25 \mathrm{~mm}$ of EPS for Test Assemblies A.2 and B.2 and 1.5-in. or $38 \mathrm{~mm}$ of EPS for Test Assemblies A.3 and B.3) increases the R-value of the base wall of that test series (A.1 and B.1) more than the R-value of the EPS foam. For example, the addition of 1 -in. $(25 \mathrm{~mm})$ of EPS to Test Assembly A.1, creating Test Assembly A.2, increases the wall assembly R-value by $4.7 \mathrm{hr}-\mathrm{ft}^{2}-{ }^{\circ} \mathrm{F} / \mathrm{Btu}\left(0.83 \mathrm{~m}^{2}-{ }^{\circ} \mathrm{C} / \mathrm{W}\right)$ while the measured R-value of the EPS, from ASTM C0518 testing, is $3.75 \mathrm{hr}-\mathrm{ft}^{2}-{ }^{\circ} \mathrm{F} / \mathrm{Btu}$ $\left(0.66 \mathrm{~m}^{2}-{ }^{\circ} \mathrm{C} / \mathrm{W}\right)$. This phenomena was observed for all four cases tested; the average additional R-value added to the test assembly was $0.80 \mathrm{hr}-\mathrm{ft}^{2}-{ }^{\circ} \mathrm{F} / \mathrm{Btu}\left(0.14 \mathrm{~m}^{2}-{ }^{\circ} \mathrm{C} / \mathrm{W}\right)$ greater than the R-value of the added sheathing. Simulations were consistent with this finding by predicting an average additional simulated $\mathrm{R}$-value of $0.94 \mathrm{hr}-\mathrm{ft}^{2}-{ }^{\circ} \mathrm{F} / \mathrm{Btu}(0.17$ $\mathrm{m}^{2}-{ }^{\circ} \mathrm{C} / \mathrm{W}$ ). 
TABLE 1 -- Comparison of Test and Sinulated Thermal Resistance Results on Twelve Wall Assemblies.

\begin{tabular}{|c|c|c|c|}
\hline \multirow{2}{*}{ Wall ID } & Test R-Value & \multicolumn{2}{|c|}{ Simulated R-Value } \\
\cline { 2 - 4 } & $\begin{array}{c}\mathrm{hr}-\mathrm{ft}^{2}-{ }^{\circ} \mathrm{F} / \mathrm{BTU}, \\
\left(\mathrm{m}^{2}-{ }^{\circ} \mathrm{C} / \mathrm{W}\right)\end{array}$ & $\begin{array}{c}\mathrm{hr}-\mathrm{ft}^{2}-{ }^{\circ} \mathrm{F} / \mathrm{BTU} \\
\left(\mathrm{m}^{2}-{ }^{\circ} \mathrm{C} / \mathrm{W}\right)\end{array}$ & $\begin{array}{c}\text { \% difference from } \\
\text { test }\end{array}$ \\
\hline A.1 & $7.81(1.38)$ & $7.68(1.35)$ & -1.7 \\
\hline A.2 & $12.52(2.21)$ & $12.18(2.15)$ & -2.7 \\
\hline A.3 & $13.85(2.44)$ & $13.87(2.44)$ & +0.1 \\
\hline B.1 & $9.56(1.68)$ & $9.74(1.72)$ & +1.9 \\
\hline B.2 & $14.11(2.49)$ & $14.57(2.57)$ & +3.3 \\
\hline B.3 & $15.72(2.77)$ & $16.35(2.88)$ & +4.0 \\
\hline C.1 & $4.2(0.74)$ & $4.09(0.72)$ & -2.4 \\
\hline C.2 & $6.8(1.2)$ & $7.3(1.29)$ & +7.4 \\
\hline C.3 & $9.0(1.59)$ & $9.6(1.69)$ & +6.7 \\
\hline D.1 & $9.2(1.62)$ & $8.9(1.57)$ & -3.4 \\
\hline D.2 & $11.8(2.08)$ & $12.0(2.11)$ & +2.0 \\
\hline D.3 & $13.9(2.45)$ & $14.0(2.47)$ & +3.4 \\
\hline
\end{tabular}

Reasons for this additional R-value were explored. The possibility exists that an additional contact resistance is created when the insulated sheathing is added to the wall assembly. However, the ASHRAE Handbook of Fundamentals [8] suggests that this contact resistance should be on the order of 0.1 to $0.2 \mathrm{hr}-\mathrm{ft}^{2}-{ }^{\circ} \mathrm{F} / \mathrm{Btu}\left(0.02\right.$ to $\left.0.04 \mathrm{~m}^{2}-{ }^{\circ} \mathrm{C} / \mathrm{W}\right)$. Since the EPS sheathing is applied to the climate side, its mean temperature is probably lower than the value originally used in the simulations (thermal performance data for all materials was measured at $75^{\circ} \mathrm{F}$ or $24^{\circ} \mathrm{C}$ ). Additional simulations were performed that indicate that temperature corrections would change the average wall assembly $\mathrm{R}$-value by $0.23 \mathrm{hr}-\mathrm{ft}^{2}-{ }^{\circ} \mathrm{F} / \mathrm{Btu}\left(0.04 \mathrm{~m}^{2}-{ }^{\circ} \mathrm{C} / \mathrm{W}\right)$. The difference in $\mathrm{R}$-value of the sheathing due to its mean temperature had a small effect but was not large enough to explain the observed differences in system $\mathrm{R}$-value.

Another possible explanation is provided by the examination of the measured surface temperatures near the thermal bridge. Fig. 3 depicts the test and simulated temperature distributions from the center of the metal stud to the center of the cavity. The depression in temperature at the steel stud is much more pronounced and impacts a greater area when no insulating sheathing is present. The presence of insulating sheathing not only reduces the heat loss locally at the stud but reduces the area thermally impacted by the stud. The presence of lateral heat flow in systems containing metal thermal bridges is described 
in the ASHRAE Handbook of Fundamentals; in fact, the ASHRAE zone method for computing the thermal performance of building systems is based on the assumption that the metal thermal bridge effects an area greater than its geometric size. Recent research [9] suggests that the area affected by the thermal bridge is a function of sheathing thermal resistance.

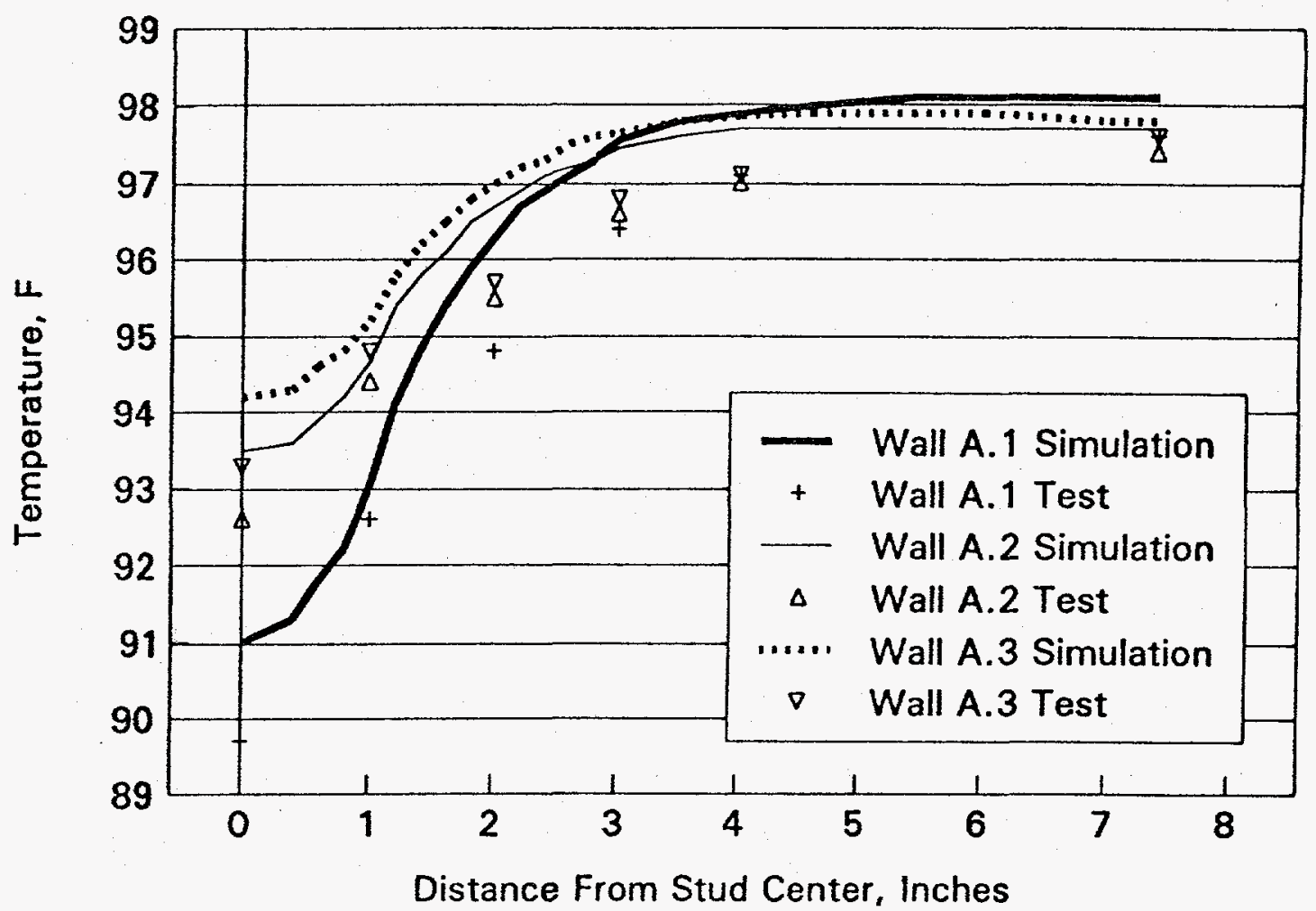

FIG. 3 -- Meter side temperature distribution from center of stud to center of cavity.

\section{Impact of the Individual Thermal Bridges}

Having validated the simulation model on the wall assemblies, the impact each individual thermal bridge had on the thermal performance of the wall assemblies was investigated through simulation. In summary, the Series A and B wall assemblies (see Fig. 1) each contained three different types of thermal bridges: steel studs, steel tracks, and fasteners that held the sheathings in place. For the Series $C$ and D wall assemblies (see Fig. 2), the thermal bridges present in the constructions were steel studs, steel tracks, fasteners, the concrete slab/shelf angle, bolts to hold the shelf angle to the slab, and masonry ties to connect the masonry blocks to the simulated brick veneer.

Table 2 contains a summary of these investigations. The wall assemblies were simulated free of the thermal effects of all of the above-listed thermal bridges. The data reported in the column entitled "Clear Wall") represents the results of these simulations. The studs were added (column entitled "w/Studs") and then the tracks included (column 
entitled "w/Studs and Tracks") to the baseline simulation model to ascertain the thermal penalty associated with each addition.

The average reduction in thermal performance of the twelve wall assemblies with the addition of studs and studs plus tracks is 19.4 and $24.2 \%$, respectively, ranging from 0 to 41 and 1 to $49 \%$ respectively. Not surprisingly, studs and tracks are nominally interchangeable with respect to thermal bridging; each stud and track in the simulated walls reduced the wall assembly R-value by 3.9 and $2.4 \%$, respectively.

TABLE 2 -- Effect of Stud and Track Thermal Bridges on the Thermal Performance of Twelve Wall Assemblies.

\begin{tabular}{|c|c|c|c|c|c|}
\hline \multirow[b]{2}{*}{ Wall ID } & \multirow[b]{2}{*}{ Clear Wall } & \multicolumn{2}{|c|}{$\begin{array}{c}\text { R-Value, hr-ft }{ }^{2} \text { of } / \text { Btu }\left(\mathrm{m}^{2}-\right. \\
\left.{ }^{\circ} \mathrm{C} / \mathrm{W}\right)\end{array}$} & \multicolumn{2}{|c|}{$\%$ of Clear Wall R-Value } \\
\hline & & w/Studs & $\begin{array}{l}\text { w/Studs \& } \\
\text { Tracks }\end{array}$ & w/Studs & $\begin{array}{l}\text { w/Studs \& } \\
\text { Tracks }\end{array}$ \\
\hline A. 1 & $12.5(2.2)$ & $8.5(1.5)$ & $7.7(1.4)$ & 68.0 & 61.6 \\
\hline A. 2 & $16.3(2.9)$ & $13.0(2.3)$ & $12.2(2.2)$ & 79.5 & 74.8 \\
\hline A. 3 & $17.9(3.2)$ & $14.6(2.6)$ & $13.9(2.4)$ & 81.6 & 77.7 \\
\hline B.I & $18.9(3.3)$ & $11.2(2.0)$ & $9.7(1.7)$ & 59.2 & 51.3 \\
\hline B.2 & $22.6(4.0)$ & $16.0(2.8)$ & $14.6(2.6)$ & 70.7 & 64.6 \\
\hline B. 3 & $24.3(4.3)$ & $17.8(3.1)$ & $16.4(2.9)$ & 73.2 & 67.5 \\
\hline C.I & $4.5(0.8)$ & $4.5(0.8)$ & $4.4(0.8)$ & 100.0 & 97.8 \\
\hline C. 2 & $9.9(1.7)$ & $9.8(1.7)$ & $9.8(1.7)$ & 99.0 & 99.0 \\
\hline C. 3 & $15.1(2.7)$ & $15.1(2.7)$ & $15.0(2.6)$ & 100.0 & 99.3 \\
\hline D.1 & $15.3(2.7)$ & $11.0(1.9)$ & $10.0(1.8)$ & 71.8 & 65.4 \\
\hline D.2 & $20.7(3.6)$ & $16.5(2.9)$ & $15.2(2.7)$ & 79.7 & 73.4 \\
\hline D. 3 & $25.8(4.5)$ & $21.7(3.8)$ & $19.9(3.5)$ & 84.1 & 77.1 \\
\hline
\end{tabular}

There is a negligible thermal penalty for adding the steel framing to the Series $\mathrm{C}$ wall assemblies. Since the cavities are uninsulated, the thermal bridge is short-circuiting across the relatively low thermal resistance of an airspace. In the Series D wall assemblies, the studs and tracks are thermally bridging through R-11 (RSI 1.94) glass fibre batts. With 
no exterior insulative sheathing (Wall D.1), the wall assembly R-value is reduced approximately $30-35 \%$. As insulating sheathing is added, the thermal bridging effect is reduced appreciably (15-25\% for Walls D.2 and D.3) because a smaller percentage of the wall assembly $\mathrm{R}$-value is being compromised by the thermal bridge.

The Series A and B wall assemblies echo these findings. As the R-Value that is compromised increases, the effect of the thermal bridge increases. In Series A and B, the studs and tracks are bridging R-11 and R-19 (RSI-1.94 and RSI-3.35) glass fibre batts, respectively. The impact of the thermal bridge is greater in the Series B walls (up to $50 \%$ in Wall B.1), and decreases as insulating sheathing is added to the wall assembly.

Additional simulations were performed to address the impact of the remaining thermal bridges. The concrete slab and shelf angle were added back into the Series $\mathrm{C}$ and $\mathrm{D}$ wall assemblies. The additional $R$-value reduction (after the reductions due to the studs and tracks) ranged from $7-36 \%$ and $11-29 \%$ for Wall Series C and D, respectively. The anchor bolts used to attach the shelf angle to the slab were also studied. Results from the simulation show that the maximum impact of the anchor bolts is about $0.3 \%$. Since they thermally bridge the low resistance concrete in the slab, this result is not surprising.

Two point-type thermal bridges were examined. Fasteners were used to attach the gypsum board and EPS foam sheathing to the steel studs in all of the wall assemblies. Fasteners had been installed on 12-in. $(300 \mathrm{~mm}$ ) centers along the studs and tracks to affix the sheathings; in total, forty-eight fasteners were used on each side of Test Series A and B walls and on the metering side of Test Series $C$ and $D$ walls. Although a temperature depression was measured during our experimental exercises, the simulations indicated that, due to the small area impacted by these thermal bridges, the reduction in wall assembly $\mathrm{R}$ value was impacted only in the third significant figure. The impact of fasteners can be ignored for the wall assemblies that we studied.

The final thermal bridge that was investigated was the masonry ties. Similar to the findings regarding the fasteners, the ties had an extremely localized effect and did not have an impact on the overall wall assembly $\mathrm{R}$-value.

\section{CONCLUSIONS}

A series of twelve guarded hot box experiments on steel stud and concrete block wall systems containing a variety of thermal bridges has been completed. These data have been used data to validate a simulation tool, and the model employed to investigate details of the experimentation. The following conclusions on the work presented have been developed.

1. The thermal performance of a variety of wall systems containing thermal bridges has been measured. The impact of thermal bridges on the thermal performance can be appreciable; in one system that we analyzed, the thermal bridge reduced the wall system R-value be approximately $50 \%$. 
2. Computer simulation was successfully employed to predict the thermal performance of the wall systems containing thermal bridges. Once tuned to include contact resistance between the sheathing and studs, the average difference between the experimental and computational tools was $3.3 \%$.

3. The addition of an insulating sheathing on a steel stud thermal bridge increases the thermal performance of the of wall system to an greater extent than the R-value of the sheathing itself. This phenomena was observed in both the experimental and numerical analyses. You obtain a "bonus" R-value by restricting lateral heat transfer and reducing the area impacted by the thermal bridge.

4. The impact of individual thermal bridges has been reviewed analytically. The average thermal performance of the wall systems that were evaluated were reduced by 20 and $24 \%$ when studs and studs plus tracks were added to the wall system containing thermal bridges has been measured. When the concrete slab was added in addition to the structural members, the thermal performance of wall systems was further reduced by $7-36 \%$.

5. Point thermal bridges such as the fasteners and concrete masonry ties evaluated in this study have a localized effect, i.e., depressed temperature, but do not appreciably impact the thermal performance of the wall system.

\section{REFERENCES}

(1) Silvers, J.P., Tye, R.P., Brownell, D.L., and Smith, S.E., "A Survey of Building Envelope Thermal Anomalies and Assessment of Thermal Break Materials for Anomaly Correction: Volume 1, Survey and Assessment," Oak Ridge National Laboratory Report ORNL/Sub/83-70376/1, Oak Ridge, TN, 1985.

(2) Enermodal Engineering, "Building Insulation System Thermal Anomalies," Final Report for ASHRAE research project 785-TRP, Waterloo, Ontario, 1996.

(3) ASTM C0236-89, Standard Test Method for Steady-State Thermal Performance of Building Assemblies by Means of a Guarded Hot Box, vol. 04.06, Annual Book of ASTM Standards, 1989.

(4) ASTM C0518-91, Standard Test Method for Steady-State Heat Flux Measurements and Thermal Transmission Properties by Means of the Heat Flow Meter Apparatus, vol. 04.06, Annual Book of ASTM Standards, 1991.

ASTM E1461-92, Standard Test Method for Thermal Diffusivity of Solids Using the Flash Method, vol. 19.02, Annual Book of ASTM Standards, 1992. 
(6) Enermodal Engineering, "FRAME: a Computer Program to Evaluate the Thermal Performance of Window Frame Systems," Version 3.0 User's Manual. Waterloo, Ontario, 1993.

(7) McGowan, A.G. and Desjarlais, A.O., "A Comparison of Thermal Bridging Calculation Methods," Proceedings of the Thermal Performance of the Exterior Envelopes of Buildings VI, American Society of Heating Refrigerating, and Air Conditioning Engineers (ASHRAE), Atlanta, GA, 1995.

(8) ASHRAE, Handbook of Fundamentals, Chapter 22, American Society of Heating Refrigerating, and Air Conditioning Engineers, Atlanta, GA, 1993.

(9) Kosny, J. and Christian, J.E., "Reducing the Uncertainties Associated with Using the ASHRAE Zone Method for R-value Calculations of Metal-Frame Walls," ASHRAE Transactions, vol. 101, Part 2, American Society of Heating Refrigerating, and Air Conditioning Engineers, Atlanta, GA, 1995. 